\title{
Oral health status of 12-year-old male schoolchildren in Medina, Saudi Arabia
}

A. Bhayat ${ }^{1}$ and M.S. Ahmad ${ }^{1}$

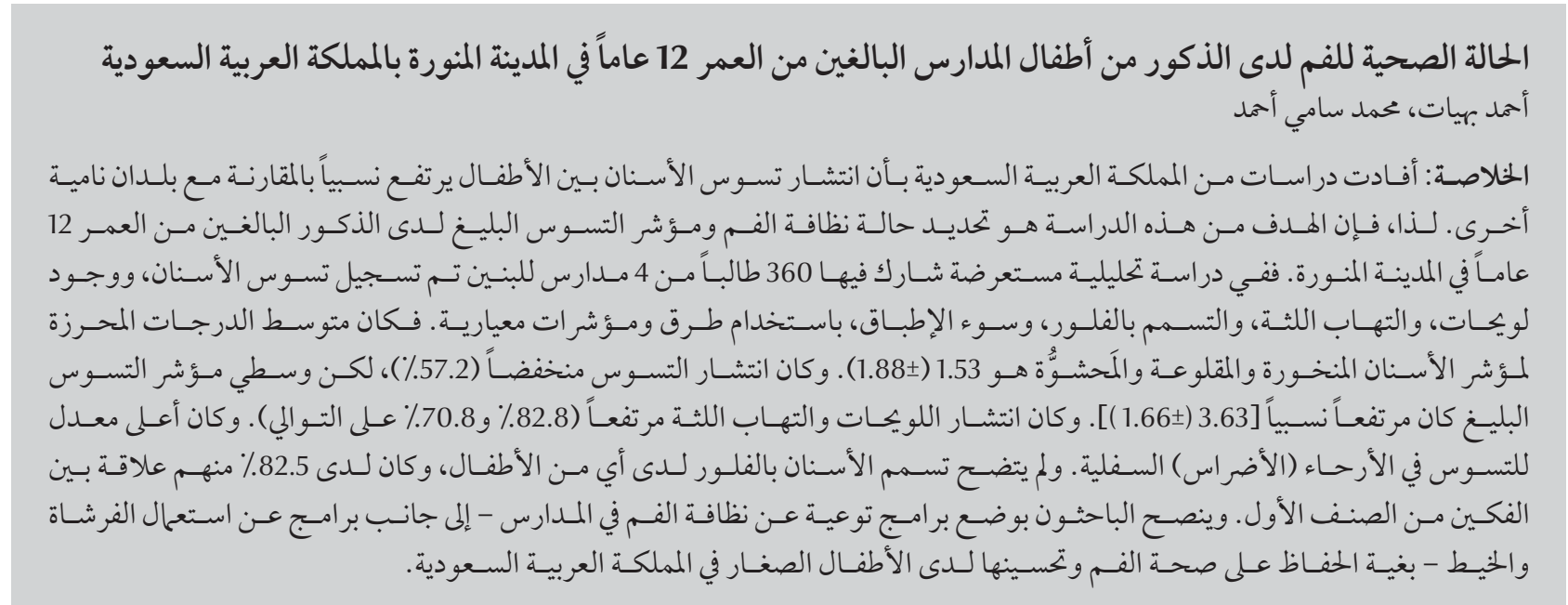

ABSTRACT Studies from Saudi Arabia have reported that the prevalence of dental caries among children is relatively high compared with other developing countries The aim was to determine the oral hygiene status and significant caries ( $\mathrm{SiC}$ ) index of 12-year-old males in Medina . In a cross-sectional, analytical study 360 students participated from 4 boys' schools. Dental caries, plaque, gingivitis, fluorosis and malocclusion were recorded using standard methods and indices. The mean DMFT score was 1.53 (SD 1.88). Caries prevalence was low (57.2\%) but the mean $\mathrm{SiC}$ index was relatively high [3.63 (SD 1.66)]. The prevalences of plaque and gingivitis were high $(82.8 \%$ and $70.8 \%$ respectively). Lower molars had the highest rate of caries. No children presented with dental fluorosis and $82.5 \%$ had a class I jaw relationship. Oral hygiene awareness programmes at schools, together with brushing and flossing programmes, are recommended in order to maintain and improve the oral health of young children in Medina

\section{Santé bucco-dentaire chez des garçons âgés de 12 ans à Médine (Arabie saoudite)}

RÉSUMÉ Selon des études menées en Arabie saoudite, la prévalence de la carie dentaire chez l'enfant est relativement élevée par rapport à d'autres pays en développement. L'objectif était de déterminer l'état de santé bucco-dentaire et les valeurs d'indice de sévérité de l'atteinte carieuse (SiC, pour Significant Caries index) chez des garçons de 12 ans à Médine ; 360 élèves de quatre écoles de garçons ont participé à une étude transversale analytique. Les caries dentaires, le tartre, la gingivite, la fluorose et les malocclusions ont été enregistrés à l'aide de méthodes et indices standards. L'indice de dents cariées, absentes ou obturées (ou DCAO) moyen était de 1,53 (ET 1,88). La prévalence des caries était faible (57,2 \%) mais l'indice SiC moyen était relativement élevé $[3,63$ (ET1,66)]. La prévalence du tartre et de la gingivite était importante (82,8\% et 70,8\%, respectivement). Les molaires inférieures avaient le taux le plus élevé de caries. Aucun enfant ne souffrait de fluorose tandis que $82,5 \%$ présentaient une malocclusion de classe I. Des programmes de sensibilisation à I'hygiène bucco-dentaire dans les établissements scolaires, associés à des programmes de brossage des dents et d'utilisation de fil dentaire sont recommandés afin de préserver mais aussi d'améliorer la santé bucco-dentaire des jeunes enfants en Arabie saoudite. 


\section{Introduction}

Good oral health is essential for the well-being and development of young children (1). The most common oral health disease affecting young children is dental caries, which is responsible for pain, speech impairment, sleep disturbances and eating and growth disorders (2). Studies from Saudi Arabia have reported a high prevalence of dental caries among children compared with other developing countries (3). In addition, these and other studies also reported high levels of oral diseases and poor oral hygiene and an urgent need for the introduction of therapeutic and preventive measures $(4,5)$. Al-Malik and Rehbini showed high levels of dental caries and recommended the introduction of an effective oral health programme for schoolchildren (6).

The significant caries $(\mathrm{SiC})$ index was developed as an adjunct to the decayed, missing and filled teeth (DMFT) index for the measurement of dental caries. Much of the literature has shown that the mean DMFT score does not accurately describe the prevalence of dental caries and often underestimates the burden of disease (7-9). Although there is a linear relationship between the mean DMFT and $\mathrm{SiC}$ indices, countries with mean DMFT between 1.0 and 8.5 were found to have mean $\mathrm{SiC}$ between 2.8 and 13.7 (9). This confirmed that, although the DMFT score of communities may meet some of the World Health Organization (WHO) guidelines, such as a DMFT $<3$ for 12-year-olds, many of the included participants still have multiple carious lesions and require extensive dental treatment. Therefore, the mean DMFT does not always reflect the true level of dental caries and this could lead to the incorrect assumption that the rate of caries is low and there is no need for the implementation of oral health programmes. Hence the $\mathrm{SiC}$ index was developed to identify communities/ populations with skewed DMFT scores and to help in the planning and monitoring of dental services and dental caries within communities (7).

No studies have reported on the oral health status of male 12-year-old children in Medina, Saudi Arabia, and this study aimed to provide baseline data which could assist in the planning of future oral health programmes. In addition, this was the first study to calculate the $\mathrm{SiC}$ index in 12-year-old male schoolchildren in Medina.

\section{Methods}

\section{Study design and sampling}

This was a cross-sectional study conducted on 12-year-old male schoolchildren. It was done between February 2013 and April 2013.

The sample size was calculated using an estimated population of 10000 12-year-old children in Medina, of which 5000 were males. These estimates were calculated based on the number of schools present in Medina. The calculation was done with a confidence interval of $95 \%$ and a margin of error of $5 \%$ with an estimated prevalence of $80 \%$. The total sample required was 357 children. It was assumed that each school would have approximately 100 children aged 12 years and therefore 4 schools were required. A list of schools was obtained from the Ministry of Education and the boys' schools were identified and stratified according to government and private funding. Two schools were then randomly selected from each stratum.

Ethical approval was obtained from the Taibah University Ethics Committee. The principal of each school was contacted and the details of the study were discussed. Once permission had been obtained, consent forms, together with a covering letter detailing the rationale of the study, were given to the children to give to their parents to sign at home. All those with signed consent were included and all information was confidential; no names were recorded on the data capture sheets.

\section{Data collection}

The clinical oral examinations were carried out in classrooms and performed under florescent room lighting with the subject sitting on a regular chair. A mirror or wooden spatula together with a round-ended probe was used according to the WHO criteria (10). The probe was only used when there was uncertainty regarding the presence of caries, as studies have shown that the use of a sharp probe could create cavitated lesions (11). For caries measurements, the DMFT index was used. If anyone had primary teeth present, these were not recorded as they were usually mobile and close to exfoliation. Plaque was recorded using the visible plaque index described by Ainamo and Bay (12). There were 2 categories, plaque absent or plaque clearly visible, scored as (0) or (1) respectively. Gingivitis was recorded using the Silness-Löe index (13). As no students had severe gingivitis and only 2 had moderate levels of gingivitis, these groups were combined with mild gingivitis. As a result, 2 groups were created, those with gingivitis present and those without gingivitis. Fluorosis was recorded using the Dean index (14) and malocclusions were classified according to Angle's classification (15). The SiC index was calculated in order to determine the mean DMFT score for the highest third of the sample (7).

There were 6 calibrated examiners and the inter- and intra-examiner reliability was measured by re-examining every 10th patient. The intra-examiner reliability was $\geq 0.95$ while the interexaminer reliability ranged between 0.85 and 0.96 . All pupils received a referral form indicating the type of treatment that they required based on the results of the clinical examination. This included oral hygiene instructions, regular follow-up visits with the dentist, restorations, extractions and polishing. 


\section{Data analysis}

The data were analysed using SPSS, version 15 software package. The descriptive analysis included means, medians and standard deviation (SD) together with frequencies and proportions.

\section{Results}

A total of 420 pupils received consent forms and of these 360 (85.7\%) completed them and were included in the study. All participants were males, the mean age was 12.1 (SD 0.97) years and just over half $(190,52.7 \%)$ were from private schools. The mean DMFT score was 1.53 (SD 1.88) and the median was 1.00. The prevalence of caries was $57.2 \%$ and the combined mean $\mathrm{SiC}$ score was 3.63 (SD 1.66). There was a statistically significant difference between the mean $\mathrm{SiC}$ scores of the the government- and private-school children $(P<0.001)($ Table 1$)$. There was also a significant difference between the government- and private-school children in the number of decayed and filled teeth and total DMFT scores, but not in the number of missing teeth. Children in government schools had more caries and higher total DMFT scores, but fewer filled teeth compared with children in private schools.

Both government- and privateschool children showed similar patterns of caries on molars (Figure 1). The caries rate was higher on the lower molars
(36 and 46) than on the upper molars and there were significantly more children with caries on molar 26 in the government compared with private schools $(P=0.04)$.

Most of the pupils presented with plaque (82.8\%) and gingivitis (70.8\%). A significant majority of respondents had a class I jaw relationship (82.5\%) $(P=0.04)$. None of the students were diagnosed with fluorosis (Table 2).

There was a strong association between the presence of plaque and gingivitis $(P<0.001)($ Table 3$)$.

\section{Discussion}

The prevalence of caries in this study (57.2\%) was within the range reported by $\mathrm{Al}$ Agili in a review of caries prevalence in Saudi Arabia (56-84\%) (3). A disturbing result is that almost $60 \%$ of children examined had at least one decayed tooth in their mouth. This has serious implications for the future in terms of treatment and rehabilitation. Preventive programmes should be implemented early in the school years in order to reduce this level.

The mean DMFT score in this study (1.53) was much lower than the range reported in the systematic review by Al Agili (1.67-2.89) (3). Possible reasons for this low score could be that the studies in his review were done more than 5 years ago. Since then much has changed as a result of social and political developments and economic growth in Saudi Arabia. This has possibly resulted in more people being able to access health services, an increase in the utilization of fluoridated toothpaste and an improvement of the public's oral health knowledge. These factors could have led to an improvement in oral hygiene and dietary intake which could have reduced the burden of oral diseases. Another possible reason is that previous research included males and females, whereas the current study was limited to males only. Studies have shown that females tend to have more dental caries than males (16) and the exclusion of females from the current study could have resulted in the lower DMFT score. The DMFT score of 1.53 was similar to other Middle Eastern countries such as Libya [1.68 (SD 1.86)] (16) and different parts of Islamic Republic of Iran [0.7 (SD 1) to 1.5 (SD 1.8)] (17)

Although this population had a mean $\mathrm{DMFT}<3$, the $\mathrm{SiC}$ index was 3.63. This shows that although the mean DMFT seemed to be low, there were still some individuals with very high DMFT scores. If the $\mathrm{SiC}$ index were not calculated, and only the DMFT index was used, it could have given a false impression of the caries status of this population and underestimated the actual need for dental treatment in this cohort of pupils. Other countries that have achieved the WHO goal of a DMFT < 3 have also reported high

\begin{tabular}{|c|c|c|c|c|c|c|c|c|}
\hline \multirow{2}{*}{$\begin{array}{l}\text { Variable } \\
\text { DMFT index }\end{array}$} & \multirow{2}{*}{$\begin{array}{c}\text { Total } \\
(n=360) \\
\text { Mean (SD) }\end{array}$} & \multicolumn{3}{|c|}{$\begin{array}{l}\text { Private school } \\
\qquad(n=190)\end{array}$} & \multicolumn{3}{|c|}{$\begin{array}{l}\text { Government school } \\
\qquad(n=170)\end{array}$} & \multirow[t]{2}{*}{$P$-value } \\
\hline & & Mean (SD) & Median & Range & Mean (SD) & Median & Range & \\
\hline Decayed & $1.30(1.82)$ & $0.98(1.47)$ & 0 & 7 & $1.65(2.10)$ & 1 & 12 & $<0.001^{\mathrm{a}}$ \\
\hline Missing & $0.02(0.17)$ & $0.02(0.16)$ & 0 & 2 & $0.02(0.19)$ & 0 & 2 & $0.567^{\mathrm{a}}$ \\
\hline Filled & $0.21(0.64)$ & $0.28(0.73)$ & 0 & 4 & $0.14(0.51)$ & 0 & 4 & $0.016^{\mathrm{a}}$ \\
\hline Total & 1.53 (1.88) & $1.28(1.55)$ & 1 & 12 & $1.81(2.15)$ & 1 & 12 & $0.045^{\mathrm{a}}$ \\
\hline SiC index & $3.63(1.66)$ & $3.09(1.21)$ & 3 & 5 & 4.24 (1.89) & 4 & 10 & $0.001^{\mathrm{b}}$ \\
\hline
\end{tabular}

${ }^{a}$ Mann-Whitney test; ${ }^{b}$ Student $t$-test.

$S D=$ standard deviation . 


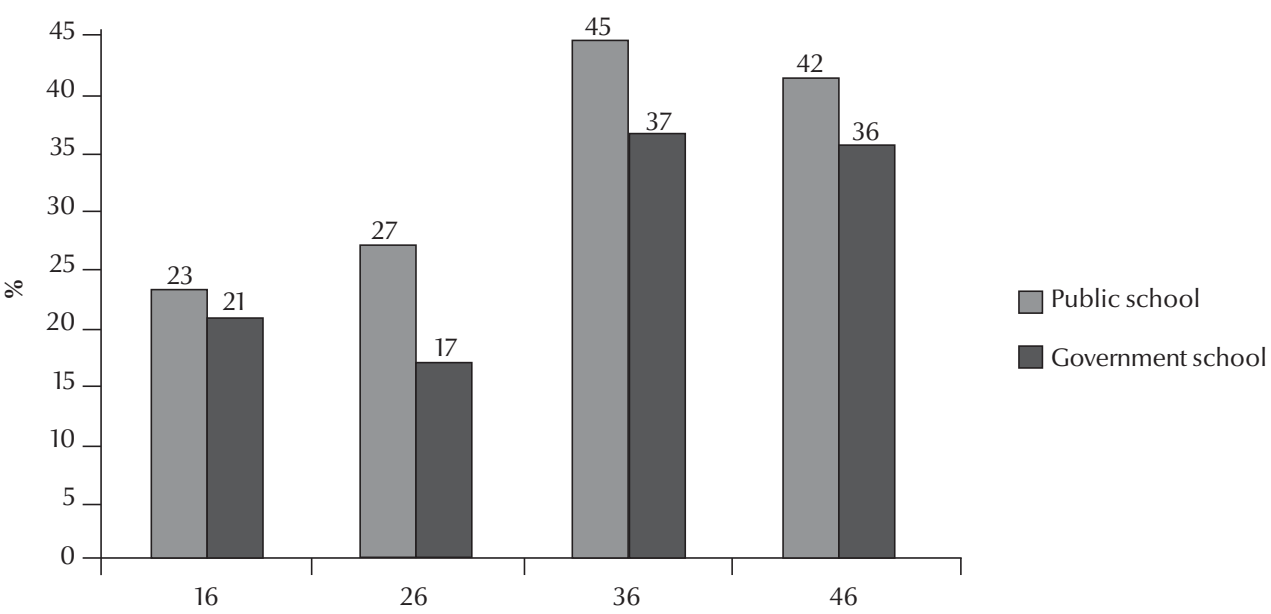

Figure 1 Prevalence of caries on first permanent molars of 12-year-old boys according to type of school attended $(n=360)$

$\mathrm{SiC}$ score and this illustrates one of the weaknesses of the DMFT index as confirmed by Nishi et al. (9). A possible reason for the $\mathrm{SiC}$ index not being used previously in other Saudi Arabian studies could be that the DMFT score was $>3$. Hence there was no need to calculate the $\mathrm{SiC}$ index and therefore comparisons of $\mathrm{SiC}$ scores between the current study and other Saudi studies are not possible.

The students who attended private schools had significantly lower levels of caries than those attending government schools. This could be attributed to the better home environment, levels of knowledge, access to dental services and oral hygiene practices in these schoolchildren, as reported by other authors (18,19). The decayed component was significantly higher in governmentschool children while the filled component was significantly higher in the private cohort. This implied that those attending the private schools had more access to dental services and received more restorations compared with government-school children. Studies done in Saudi Arabia and abroad have shown a direct relationship between utilization of dental services and the socioeconomic status and educational level of the parents $(20,21)$. As a result, private-school children visited the dentist more often and received treatment for their carious teeth in the form of fillings. This reduced their decayed component and increased their filled component of the DMFT index. The $\mathrm{SiC}$ index was also significantly

\begin{tabular}{|c|c|c|c|c|c|c|c|c|}
\hline \multirow[t]{2}{*}{ Variable } & \multicolumn{2}{|c|}{$\begin{array}{c}\text { Total } \\
(n=360)\end{array}$} & \multicolumn{2}{|c|}{$\begin{array}{l}\text { Private school } \\
\quad(n=190)\end{array}$} & \multicolumn{2}{|c|}{$\begin{array}{l}\text { Government school } \\
\qquad(n=170)\end{array}$} & \multirow[t]{2}{*}{$x^{2}$} & \multirow[t]{2}{*}{$P$-value } \\
\hline & No. & $\%$ & No. & $\%$ & No. & $\%$ & & \\
\hline \multicolumn{9}{|l|}{ Plaque } \\
\hline Absent & 62 & 17.2 & 26 & 13.7 & 36 & 21.2 & \multirow[t]{2}{*}{3.53} & \multirow[t]{2}{*}{0.06} \\
\hline Present & 298 & 82.8 & 164 & 86.3 & 134 & 78.8 & & \\
\hline \multicolumn{9}{|l|}{ Gingivitis } \\
\hline Absent & 105 & 29.2 & 59 & 31.1 & 46 & 27.1 & \multirow[t]{2}{*}{0.69} & \multirow[t]{2}{*}{0.41} \\
\hline Present & 255 & 70.8 & 131 & 68.9 & 124 & 72.9 & & \\
\hline \multicolumn{9}{|c|}{ Malocclusion } \\
\hline Class I & 297 & 82.5 & 153 & 80.5 & 144 & 84.7 & \multirow[t]{3}{*}{0.72} & \multirow[t]{3}{*}{0.04} \\
\hline Class II & 33 & 9.2 & 22 & 11.6 & 11 & 6.5 & & \\
\hline Class III & 30 & 8.3 & 15 & 7.9 & 15 & 8.8 & & \\
\hline \multicolumn{9}{|l|}{ Fluorosis } \\
\hline Absent & 360 & 100.0 & 190 & 100.0 & 170 & 27.6 & & \\
\hline Present & 0 & 0.0 & 0 & 0.0 & 0 & 0.0 & 0.89 & 0.34 \\
\hline
\end{tabular}




\begin{tabular}{|c|c|c|c|c|}
\hline \multirow[t]{3}{*}{ Plaque } & \multicolumn{4}{|c|}{ Gingivitis } \\
\hline & \multicolumn{2}{|c|}{ Absent } & \multicolumn{2}{|c|}{ Present } \\
\hline & No. & $\%$ & No. & $\%$ \\
\hline Absent & 53 & 14.7 & 9 & 2.5 \\
\hline Present & 52 & 14.4 & 246 & 68.3 \\
\hline
\end{tabular}

$\chi^{2}=114.98 ; P<0.001$.

higher among the government-school children; this indicates that the caries among these children was more severe compared with private-school children.

The prevalences of plaque (82.8\%) and gingivitis $(70.8 \%)$ were similar to another Saudi study and this could be due to poor oral hygiene practices and irregular brushing patterns by students (22). The strong association between those with plaque and gingivitis could be explained by the fact that those with higher plaque levels would have more inflammation and hence a higher likelihood of gingivitis.

The lower molars were more commonly affected by caries than the upper molars and this was consistent with another study (23). Possible reasons include their early eruption, the presence of deep pits and fissures, their larger occlusal surface and gravity (24).

The vast majority of respondents had a class I jaw relationship (82.5\%) and this was similar to other studies, which reported a prevalence of between $77 \%$ and $90 \%(25,26)$. It must be noted, however, that these and most other studies that determined the prevalence of malocclusion were done on children attending orthodontic clinics. Hence direct comparisons cannot be made.
No child was diagnosed with fluorosis and this could be due to the fact that most of the population of Medina consumes bottled water.

There were some limitations to the study. A total of 360 pupils agreed to participate out of 420. Many of the pupils were absent on the days of the screening and hence could not be included in the study. At one of the schools, the scheduled screening date was set for the last week before the midterm vacation; hence many pupils were absent. This could be one explanation for not having a higher response rate. Schools in Saudi Arabia are segregated according to sex. Males are not allowed to enter the female schools and vice versa. Since the examiners were males, the sample consisted of males and these results are therefore not representative of all 12-year-olds in Medina. Since the DMFT index only measures frank caries, early lesions or white spots were not classified as carious and this could have underestimated the burden of dental caries in this population.

\section{Conclusions}

Although the caries prevalence was low compared with other Saudi Arabian studies, the $\mathrm{SiC}$ index was relatively high. Many students had poor oral hygiene, which was confirmed by the high prevalence of plaque and gingivitis. The lower molars were more commonly affected by caries compared with the upper molars. Children in government schools had significantly more caries than their counterparts in private schools. No children were diagnosed with fluorosis.

We recommend conducting a similar study for female schoolchildren in Medina to identify the burden of disease among them. The results also indicate that there is a need for oral hygiene awareness programmes at schools, together with brushing and flossing programmes, in order to maintain and improve oral health of young children in Saudi Arabia. Teachers should be informed about the importance of oral hygiene so that they can monitor and maintain oral hygiene programmes.

\section{Acknowledgements}

The authors would like to thank Drs Ahmed Abdulrahim Marghalani and Mohammed Mahmoud Sarhan for their invaluable assistance in the liaising with the schools and helping collect data.

In addition we would like to thank the 2013 final-year dental students of Taibah Dental College for assisting with the data collection, entering and analysis.

Funding: There was no significant financial support for this work that could have influenced its outcome.

Competing interests: None declared.

\section{References}

1. Malden PE, Thomson WM, Jokovic A, Locker D. Changes in parent-assessed oral health-related quality of life among young children following dental treatment under general anesthetic. Community Dent Oral Epidemiol. 2008;36:108-17. PMID:18333874

2. Schroth RJ, Harrison RL, Moffatt MEK. Oral health of indigenous children and the influence of early childhood caries on childhood health and well-being. Pediatr Clin North Am. 2009;56:1481-99. PMID:19962032

3. Al Agili DE. A systematic review of population-based dental caries studies among children in Saudi Arabia. Saudi Dent J. 2013;25:3-11. PMID:23960549

4. Al-Banyan RA, Echeverri EA, Narendran S, Keene HJ. Oral health survey of 5-12-year-old children of National Guard 
employees in Riyadh, Saudi Arabia. Int J Paediatr Dent. 2000;10:39-45. PMID:11310125

5. Al-Jobair AM, Al-Sadhan SA, Al-Faifi AA, Andijani RI. Medical and dental health status of orphan children in central Saudi Arabia. Saudi Med J. 2013;34:531-6. PMID:23677271

6. Al-Malik MI, Rehbini YA. Prevalence of dental caries, severity, and pattern in age 6 to 7 -year-old children in a selected community in Saudi Arabia. J Contemp Dent Pract. 2006;7:46-54. PMID:16685294

7. Bratthall D. Introducing the Significant Caries Index together with a proposal for a new oral health goal for 12-year-olds. Int Dent J. 2000;50:378-84. PMID:11197197

8. Antunes JLF, Narvai PC, Nugent ZJ. Measuring inequalities in the distribution of dental caries. Community Dent Oral Epidemiol. 2004;32:41-8. PMID:14961839

9. Nishi M, Stjernswärd J, Carlsson P, Bratthall D. Caries experience of some countries and areas expressed by the Significant Caries Index. Community Dent Oral Epidemiol. 2002;30:296301. PMID:12147171

10. Oral health surveys: basic methods. Geneva: World Health Organization; 1997.

11. Kuhnisch J, Dietz W, Stosser L, Hickel R, Heinrich-Weltzien R. Effects of dental probing on occlusal surfaces-a scanning electron microscopy evaluation. Caries Res. 2007;41:43-8. PMID:17167258

12. Ainamo J, Bay I. Problems and proposals of recording gingivitis and plaque. Int Dent J. 1975;25:229-35. PMID:1058834

13. Löe H, Silness J. Periodontal disease in pregnancy I. Prevalence and severity. Acta Odontol Scand. 1963;21:533-51. PMID:14121956

14. Dean HT. The investigation of physiological effects by the epidemiological method. In: Moulton FR, editor. Fluoride and dental health. Washington (DC): American Association for the Advancement of Science; 1942. pp. 23-31.

15. Angle EH. Classification of malocclusion. Dent Cosmos. 1988;41:248-64.
16. Huew R, Waterhouse PJ, Moynihan PJ, Maguire A. Prevalence and severity of dental caries in Libyan schoolchildren. Int Dent J. 2011;61:217-23. PMID:21851354

17. Meyer-Lueckel H, Bitter K, Shirkhani B, Hopfenmuller W, Kielbassa AM. Prevalence of caries and fluorosis in adolescents in Iran. Quintessence Int. 2007;38:459-65. PMID:17625628

18. Al-Haddad AM, Bin Ghouth AS, Hassan HS. Distribution of dental caries among primary school children in Al-Mukalla area, Yemen. J Dent. 2006;3:195-8.

19. Lulić-Dukić O, Jurić H, Dukić W, Glavina D. Factors predisposing to early childhood caries (ECC) in children in pre-school age in the city of Zagreb, Croatia. Coll Antropol. 2001;25:295302. PMID: 11787553

20. Al Agili DE, Niazy HA, Pass MA. Prevalence and socioeconomic determinants of dental sealant use among schoolchildren in Saudi Arabia. East Mediterr Health J. 2012;18:1209-16. PMID:23301395

21. Al-Hussyeen. Factors affecting utilization of dental health services and satisfaction among adolescent females in Riyaadh city. Saudi Dent J. 2010;22:19-25. PMID:23960475

22. Al-Sadhan SA. Oral health practices and dietary habits of intermediate school children in Riyadh, Saudi Arabia. Saudi Dent J. 2003;15:81-7.

23. Wyne AH. The bilateral occurrence of dental caries among 1213 and 15-19 year old school children. J Contemp Dent Pract. 2004;5:42-51. PMID:14973559

24. Al-Samadani KH, Ahmad MS. Prevalence of first permanent molar caries in and its relationship to the dental knowledge of 9- 12-year olds from Jeddah, Kingdom of Saudi Arabia. ISRN Dent. 2012; doi: 10.5402/2012/391068 PMID:22461990

25. Albarakati SF, Taher S. Malocclusion traits in Saudi females seeking orthodontic treatment. Pak Oral Dent J. 2010;30:12732.

26. Kaur H, Pavithra US, Abraham R. Prevalence of malocclusion among adolescents in South Indian population. J Int Soc Prevent Communit Dent. 2013;3:97-102. PMID:24778988 